Laporan Kasus

\title{
Skin Flaps and Graft In Eyelid Reconstruction
}

\author{
Khairiah Nevrianty ${ }^{1}$, Hendriati ${ }^{2}$
}

\begin{abstract}
Abstrak
Rekonstruksi kelopak mata merupakan salah satu operasi mata yang paling menantang karena menuntut kemungkinan hasil fungsional dan kosmetik yang terbaik. Flap dan graft merupakan suatu teknik pada bedah plastik dan rekonstruksi dengan tujuan untuk mengisi dan memperbaiki defek pada suatu luka tertentu. Prosedur skin flap dan graft dengan teknik semisirkular flap merupakan salah satu prosedur untuk rekonstruksi dengan defek luas pada kelopak mata bawah. Dilaporkan seorang pasien perempuan usia 55 tahun, dikonsulkan dari subbagian Tumor dengan diagnosa karsinoma sel skuamosa kelopak bawah mata kanan, terdapat massa pada palpebra inferior dengan ukuran $\pm 40 \mathrm{~mm} \times 25 \mathrm{~mm} \times 15 \mathrm{~mm}$ dengan bola mata dalam batas normal. Identifikasi luas defek setelah wide excision adalah sekitar $45 \mathrm{~mm} \times 30 \mathrm{~mm}$ yang melibatkan margo kelopak mata dan kantus. Semicircular flap-pedicle flap dengan graft mukosa mulut dilakukan pada pasien ini. Dengan teknik ini telah dapat merekonstruksi kelopak mata inferior sehingga secara kosmetik dapat diterima oleh pasien. Terdapat komplikasi yang ditemukan yaitu lagoftalmus sebesar $3 \mathrm{~mm}$ setelah 1 bulan post operasi. Simpulan dari laporan kasus ini adalah penggunaan skin flap dan graft pada rekontruksi kelopak mata dapat menjadi solusi bila defek terlalu besar untuk dilakukan penutupan atau tidak dapat dilakukan penutupan secara primer untuk mengembalikan anatomi dan fungsi kelopak mata.
\end{abstract}

Kata kunci: skin flaps, graft, lamela anterior, lamela posterior, rekonstruksi kelopak mata, semicircular flap

\begin{abstract}
Eyelid reconstruction is one of the most challenging eye surgeries because it demands the best possible functional and cosmetic results. Flap and graft is a technique in plastic and reconstructive surgery aimed to fill and repair defects in particular wound. The skin flap and graft procedure with a semicircular flap technique is one procedure for reconstruction with a wide defect in the lower eyelid. Reported a fourty five years old woman was consulted from the Tumor subdivion with diagnosis of lower eyelid squamous cell carcinoma, there a mass of 40mmx $25 \mathrm{~mm} \times 15 \mathrm{~mm}$ in inferior palpebra. The identification of defect area after wide excision was around $45 \mathrm{~mm} \times 30 \mathrm{~mm}$ which involved eyelids margin and canthus with eyeball within normal limits. Semicircular flap-pedicle flap with oral mucosal graft was performed in these patients. This technique had been able to repair the inferior eyelid so that it could be cosmetically accepted by the patient. There was a complication found, namely $3 \mathrm{~mm}$ lagophthalmus after 1 month postoperatively. The conclusion of this case report is the use of skin flaps and graft) on eyelid reconstruction can be a solution with large defect or if the defect cannot be closed in a primary way to restore the anatomy and function of the eyelids.
\end{abstract}

Keywords: skin flaps, graft, lamellae anterior, lamellae posterior, eyelid reconstruction, semicircular flap

Affiliasi penulis: 1. Program Pendidikan Dokter Spesialis-1 IImu Penyakit Mata Fakultas Kedokteran Universitas Andalas Padang (FK Unand), 2. Bagian IImu Kesehatan Mata FK Unand.

Korespondensi: khairiahnevrianty@gmail.com, Telp: 082161471366

\section{PENDAHULUAN}

Trauma dan eksisi tumor pada kelopak mata merupakan penyebab penting defek pada kelopak mata selain kelainan kongenital yang memerlukan perbaikan dan rekonstruksi. Pemahaman tentang prinsip-prinsip dasar dalam perbaikan dan rekonstruksi kelopak mata akan sangat membantu dalam mengembalikan fungsi dasar kelopak mata. ${ }^{1}$

Beberapa metode dapat menjadi pilihan yang tepat untuk rekonstruksi pada defek kelopak mata tertentu. Pilihan prosedur tergantung pada usia pasien, kondisi kelopak mata, ukuran dan posisi defek 
serta pengalaman operator. Metode yang digunakan dapat bervariasi, tergantung pada kelopak atas atau bawah yang terlibat, anterior atau posterior lamella terlibat dan juga dengan tingkat defek yang terjadi. ${ }^{2}$

Defek yang terlalu besar untuk dilakukan penutupan atau tidak dapat dilakukan penutupan secara primer, penggunaan skin flap dan graft pada rekontruksi kelopak mata dapat menjadi solusi untuk mengembalikan anatomi dan fungsi kelopak mata. ${ }^{3}$ Flap dan graft merupakan suatu teknik pada bedah plastik dan rekonstruksi dengan tujuan untuk mengisi dan memperbaiki defek pada suatu luka tertentu. ${ }^{4}$

Lamella anterior yang mengalami defek dapat direkonstruksi dengan basic local flap. Flap adalah apabila jaringan yang diambil dari sebuah donor (pemberi) dan dipindahkan ke resipien (penerima) dengan vaskularisasi yang utuh sehingga dapat menghidupi dirinya sendiri karena memiliki pembuluh

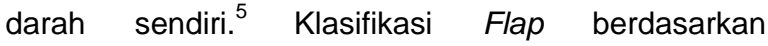
vaskularisasi antara lain Random Pattern Skin Flaps dan Axial Pattern Skin Flaps, sedangkan Klasifikasi Flap yang digunakan berdasarkan pergerakan yang dominan pada rekonstruksi kelopak mata, yaitu Advancement Flaps, Rotation Flaps (Flap Semisirkular) danTransposition Flaps. ${ }^{6}$

Defek pada lamela posterior dapat direkonstruksi dengan free autogenous composite grafts seperti tarsoconjunctival free graft, mukosaseptal kartilago, mukosa palatum durum, advancement or rotational conjunctival flaps dan periosteal strips. Pilihan terbaik adalah dengan tarsoconjunctival free graft. ${ }^{7}$ Graft adalah apabila jaringan yang diambil dari sebuah donor dan dipindahkan ke resipien tidak disertai dengan dengan vaskularisasi yang utuh sehingga memerlukan vascular bed yang baik agar dapat tumbuh pada resipiennya. ${ }^{8}$

\section{KASUS}

Seorang pasien perempuan, usia 55 tahun dikonsulkan dari subbagian Tumor dengan diagnosis karsinoma sel skuamosa kelopak bawah mata kanan. Pasien dengan keluhan tampak benjolan pada kelopak bawah mata kanan sejak 3 bulan yang lalu. Tajam penglihatan mata kanan (OD) 5/10 dan mata kiri (OS) $5 / 7$, segmen anterior dan posterior dalam batas normal, posisi bola mata normal dan tidak terdapat restriksi pada pergerakan bola mata. Pada pemeriksaan palpebra inferior kanan tampak massa dengan ukuran \pm 40mmx 25mmx15mm (Gambar 1), dengan permukaan teraba rata, konsistensi kenyal padat dan sulit digerakkan dari dasarnya. Identifikasi luas defek pada palpebra inferior setelah wide excision adalah sekitar $45 \mathrm{~mm} \times 30 \mathrm{~mm}$ full thickness yang melibatkan margo kelopak mata dan kantus. Prosedur Rotation flap(flap semisirkular) dengan graft mukosa mulut dilakukan pada pasien ini.

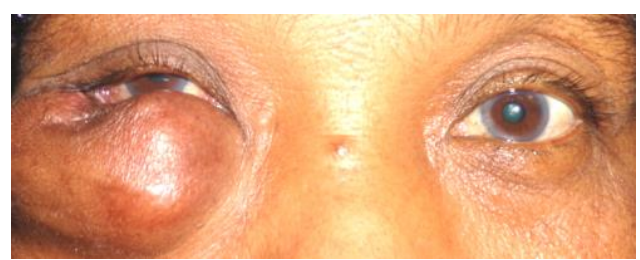

Gambar 1. Massa pada kelopak bawah mata kanan

Teknik flap semisirkular dilakukan dengan memindahkan flap yang diambil pada regio pelipis sebanyak sebesar defek yang akan ditutup pada palpebra inferior. Pada kasus ini dilakukan insisi pada pelipis kanan pasien dengan ukuran $\pm 45 \mathrm{~mm} \times 30 \mathrm{~mm}$ lalu dijahitkan pada daerah luka palpebra inferio untuk merekonstruksi lamela anterior. Jahit area tempat pengambilan flap.

Pengambil graft mukosa bibir diakukan sayatan berbentuk persegi panjang berukuran $3 \mathrm{~cm} \times 1 \mathrm{~cm}$ pada mukosa bibir untuk graft, lakukan balloning dengan pehacain agar mukosa terpisah dari jaringan dibawahnya. Ambil graft mukosa bibir dan rendam dalam cairan campuran $\mathrm{NaCl}$ dan Gentamycine. Identifikasi konyungtiva yang tersisa, jahitkan mukosa bibir pada sisa konyungtiva untuk membuat lamela posterior.

Penutupan luka operasi dilakukan dengan perban disertai penekanan agar skin flaps dan graft mengalami attachment dengan baik dengan resipiennya. Gaya geser atau pergerakan dapat memisahkan graft yang baru terhadap jaringan dibawahnya dan mencegah kontak yang diperlukan untuk hubungan antar kapiler dan kelangsungan hidup selanjutnya, sehingga pergeseran harus diminimalkan sebaik mungkin.

Follow up pasien post operasi dilakukan pada hari ketiga, setelah satu minggu, dua minggu dan setelah satu bulan. Follow up pertama dilakukan setelah hari ketiga setelah tindakan operasi karena 
tindakan rekonstruksi ini menggunakan flap dan graft yang membutuhkan waktu untuk terjadinya aposisi antara flap atau graft dengan resipiennya. Pada follow up hari ketiga (Gambar 2), palpebra mata kanan tampak edem dan hematom, hechting flap pada palpebra inferior dalam kondisi baik, tidak terdapat proses supurasi dan flap tidak tampak nekrosis. Tampak konyungtiva bulbi diregio inferior kemosis dengan lagoftalmus berukuran $5 \mathrm{~mm}$. Pasien diperbolehkan untuk rawat jalan, diberikan obat antibiotik topikal, antibiotik oral serta analgetik oral.

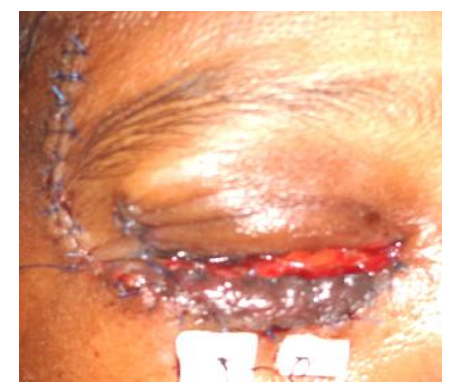

Gambar 2. Follow up 3 hari post operasi

Satu minggu post operasi (Gambar 3), tampak edem palpebra mata kanan sudah berkurang, hechting flap pada palpebra inferior dalam kondisi baik, tidak terdapat proses supurasi dan flap tampak hidup yang ditandai dengan adanya jaringan granulasi. Tampak kemosis konyungtiva dan lagoftalmus sebesar $5 \mathrm{~mm}$.

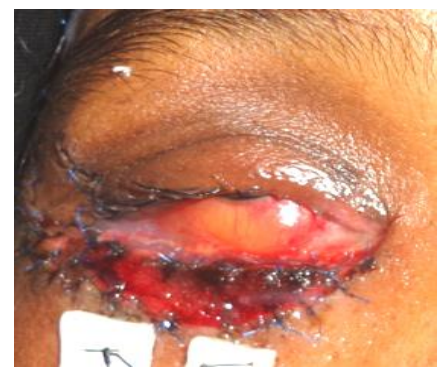

Gambar 3. Follow up 1 minggu post operasi

Pada dua minggu post operasi (Gambar 4), edem maupun hematom pada palpebra tampak berkurang, hechting flap pada palpebra inferior dalam kondisi baik, tidak terdapat proses supurasi dan flap tampak hidup yang ditandai dengan adanya jaringan granulasi. Tampak kemosis konyungtiva dan lagoftalmus. Hehting pada palpebra dibuka secara selang seling.

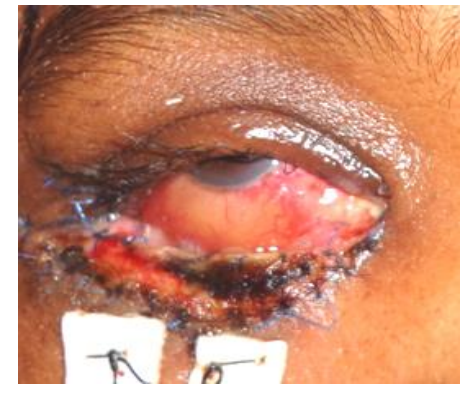

Gambar 4. Follow up 2 minggu post operasi

Follow up setelah satu bulan tindakan operasi (Gambar 5), Tampak jaringan flap pada palbera inferior telah menyatu dengan baik dengan kulit palpebra. Tidak tampak perbedaan warna antara kulit palpebra dengan jaringan flap. Tidak tampak kemosis konyungtiva dan ditemukan lagoftalmus sebesar $3 \mathrm{~mm}$.

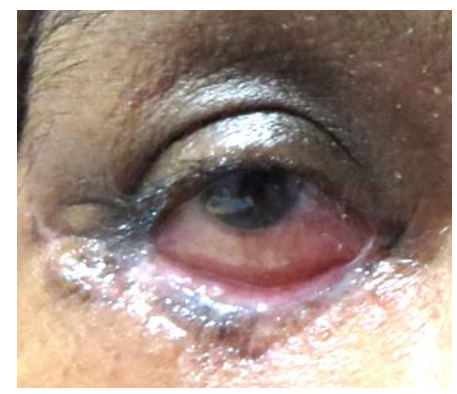

Gambar 5. Follow up 1 bulan post operasi

\section{PEMBAHASAN}

Tujuan rekonstruksi palpebra adalah untuk mengembalikan fungsi normal palpebra sebagai proteksi bola mata dan restorasi kosmetik yang baik. Pemahaman yang baik terhadap anatomi kelopak mata dapat memantapkan prinsip-prinsip dasar dalam perbaikan dan rekonstruksi kelopak mata yang akan sangat membantu dalam mengembalikan fungsi dasar kelopak mata. $^{2}$

Defek yang terjadi pada kasus ini disebabkan karena paska wide eksisi karsinoma sel skuamosa palpebra inferior mata kanan. Penyebab defek pada kelopak mata dapat terjadi karena trauma, paska eksisi tumor, defek kongenital ataupun penyakit autoimun. Trauma dan eksisi tumor pada kelopak mata merupakan penyebab penting defek pada kelopak mata yang memerlukan perbaikan dan rekonstruksi. $^{3}$ 
Defek yang terjadi pada kasus ini setelah tindakan tergolong defek yang luas yaitu sebesar $45 \mathrm{~mm}$ pada palpebra inferior (>65\%). Defek palpebra dapat di klasifikasikan berdasarkan ukuran defeknya yang dipengaruhi juga oleh usia dan laxity. Pada pasien muda, defek terbagi menjadi defek kecil sebesar $25-35 \%$, defek moderate sebesar $35-45 \%$ dan defek luas sebesar $>55 \%$. Pada pasien tua atau dengan laxity dibagi menjadi defek kecil sebesar 35$45 \%$, moderate sebesar $45-55 \%$ dan defek luas sebesar $>65 \%$. $^{2,3}$

Pemilihan tekhnik rekonstruksi palpebra tergantung pada usia pasien, ukuran dan kedalaman defek serta posisi defek serta, status visus pada mata yang lain, status kesehatan pasien serta pengalaman operator. Metode penutupan pada defek kelopak mata full-thickness tergantung pada lokasi dan bentuk luka. ${ }^{4}$

Sebagian besar defek disebabkan karena reseksi keganasan yang berlokasi di kelopak mata bawah, defek yang terbentuk paling sering ditemukan berbentuk baji (wedge) seperti bentuk defek pada kasus ini. Defek berbentuk baji yang melibatkan hingga lebih dari $50 \%$ pada margin kelopak mata dapat ditutup terutama pada pasien yang berusia tua. Kantolisis lateral diperlukan jika tepi defek tidak dapat dibawa bersama-sama dengan mudah. Tepi defek harus tegak lurus dengan margin kelopak mata sepanjang ketinggian penuh dari tarsus untuk menghindari notching. ${ }^{7,8}$

Metode yang digunakan dapat bervariasi, tergantung pada apakah kelopak atas atau bawah yang terlibat, apakah anterior atau posterior lamella terlibat dan juga dengan tingkat defek yang terjadi. Defek pada kasus ini meliputi lamela anterior dan posterior. Kedua lamela baik anterior dan posterior harus direstorasi secara adekuat dan setidaknya salah satu lamela harus memiliki vaskularisasi yang baik pada graftnya untuk mendukung graft yang kurang vaskularisasinya bila diperlukan. ${ }^{9,10}$

Rekontruksi pada defek lamela anterior membutuhkan flap dengan warna kulit dan persamaan tekstur kulit yang optimal, meminimalkan sikatrik, dan meminimalkan tegangan vertikal pada margo palpebra dan tidak menyebabkan malposisi palpebra post operasi. Flap yang diambil dari daerah pelipis sekitar kelopak mata ipsilateral ataupun kontralateral akan memiliki kecocokan yang terbaik. ${ }^{10,11}$

Flap adalah apabila jaringan yang diambil dari sebuah donor (pemberi) dan dipindahkan ke resipien (penerima) dengan vaskularisasi yang utuh sehingga dapat menghidupi dirinya sendiri karena memiliki pembuluh darah sendiri. Pada tahun 1500, Tagliacozzi menggunakan random flap pertama kalinya berupa random pedicle flap yang diambil dari lengan atas untuk rekonstruksi hidung. ${ }^{10,11}$

Flap menjadi pilihan pada keadaan yang membutuhkan penutupan defek dengan jaringan vaskularisasi resipien yang kurang, untuk penutupan defek pada jaringan vital, seperti rekonstruksi full thickness pada kelopak mata, bibir, telinga, hidung dan pipi. Pasokan darah dari kulit yang terkandung sebagian besar di dermal dan pleksus subdermal berasal dari dua sumber utama yaitu sistem vaskular muskulokutaneus dan sistem vaskular kulit langsung. ${ }^{10,11}$

Klasifikasi Flap berdasarkan vaskularisasi yaitu Random Pattern Skin Flaps dan Axial Pattern Skin Flaps, sedangkan klasifikasi Flap yang digunakan berdasarkan pergerakan yang dominan pada rekonstruksi kelopak mata, yaitu : ${ }^{6}$

a. Advancement Flaps. Pada advancement flaps, memiliki konfigurasi linear atau rektangular (gambar 6). Advancement flaps, dilakukan pergerakan langsung kearah depan atau dimajukan menuju defek tanpa di rotasi ataupun pergerakan ke arah lateral. $^{6}$

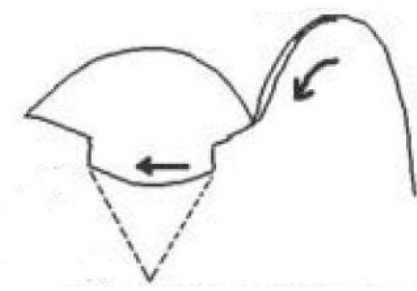

Gambar 6. Pola Advancement Flaps ${ }^{6}$

b. Rotation Flaps. adalah flap semisirkular, dilakukan rotasi terhadap flap untuk menutupi defek (Gambar 7). Lokasi donor dapat ditutup dengan skin graft atau dilakukan dengan penjahitan langsung. ${ }^{6}$ 


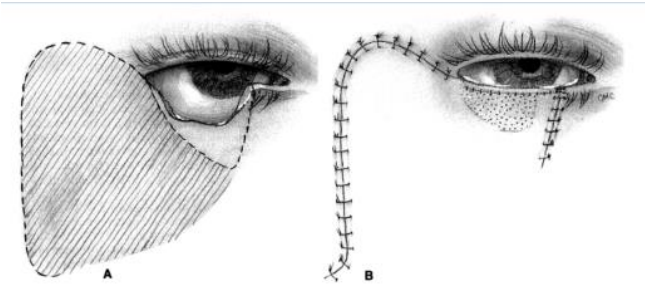

Gambar 7. Pola rotation flaps ${ }^{6}$

c. Transposition Flaps. Pada transposisi flap, flaps dipindahkan kearah lateral atau ke arah defek untuk menutupi defek. ${ }^{6}$

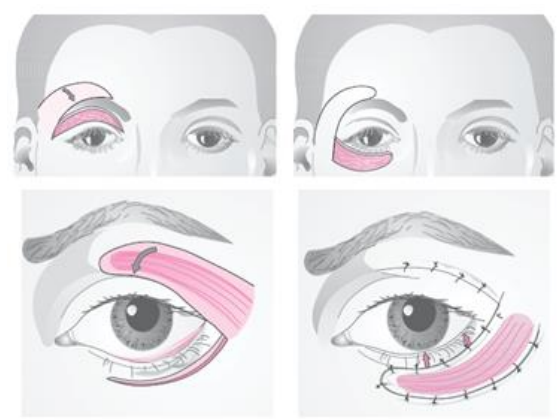

Gambar 8. Pola transposition flaps ${ }^{6}$

Dalam prakteknya kedua teknik terakhir ini dapat digabungkan untuk defek derajat tertentu.

Kelebihan penggunaan flap pada rekontruksi kelopak mata antara lain : ${ }^{12}$

- Lamela anterior dapat direkonstruksi dengan sedikit kontraktur selama fase penyembuhan

- Pasokan vaskular yang adekuat didasar flap meningkatkan kelangsungan hidup jaringan dibandingkan dengan graft.

- Hasil kosmetik berupa kecocokan warna dan tekstur dapat maksimal

Pada pasien ini karena berusia tua dan peningkatan laxity palpebra, maka prosedur rekonstruksi lamela anterior yang dipilih adalah semisirkular flaps (Rotation flaps). Flap dijahit di atas lamela posterior.

Tujuan penggunaan pengganti lamela posterior adalah memberi permukaan mukosa yang tebal dan menopang palpebra. Defek lamela posterior dapat direkonstruksi dengan free autogenous composite grafts seperti tarsoconjunctival free graft, mukosa-septal kartilago, mukosa palatum durum, advancement or rotational conjunctival flaps dan periosteal strips. Pilihan terbaik adalah dengan tarsoconjunctival free graft. Pilihan lain dapat diambil dari mukosa pipi, mukosa bibir, mucopericondrium palatum durum dan nasal, atau kartilago aurikula. Pada kasus ini, mukosa bibir dipilih sebagai pengganti lamella posterior untuk memopang palpebra. ${ }^{7,9}$

Pada follow up, pasien ini memerlukan perlakuan yang berbeda karena proses rekonstruksi kasus ini menggunakan skin flaps dan graft. Tindakan follow up dan keberhasilan suatu graft menempel dengan resipien adalah suatu mekanisme yang disebut dengan skin graft take. 'Take' adalah suatu proses yang akan menghasilkan reattachment dan revascularization pada graft, yang terdiri dari 3 fase, yaitu: fase imbibisi plasma, fase inokulasi dan pertumbuhan ke arah dalam dari kapiler serta fase revaskularisasi. Terjadinya attachment antara skin flaps dan graft pada proses rekonstruksi memerlukan waktu agar dapat menempel dan hidup dengan baik terhadap resipiennya. ${ }^{13,14}$

Pada kasus ini, follow up pertama kali dan membuka perban dilakukan setelah hari ketiga setelah tindakan operasi karena pada hari ketiga telah terjadi proses attachment terhadap resipien. Keberhasilan penggunaan skin flaps dan graft pada rekonstruksi dipengaruhi oleh beberapa faktor yaitu status jaringan resipien, kondisi ada atau tidaknya infeksi, tidak adanya pergeseran dan status hemostasis. Skin flap dan graft membutuhkan oksigen dan nutrisi untuk bertahan hidup. Kelangsungan hidup jangka panjang skin flaps dan graft tergantung pada pasokan dari pembuluh darah baru yang terbentuk dari luka terhadap graft. Ketika jaringan luka tidak memiliki cukup asupan oksigen dan nutrisi yang tersedia akan mengakibatkan kegagalan. ${ }^{10,15}$

Fenomena bridging pada resipien dapat ditemukan, yaitu pasokan darah dari jaringan sekitar lebih dari cukup untuk memberikan vaskularisasi terhadap skin flaps dan graft dan berhasil memberikan penutupan yang baik terhadap defek. Keadaan resipien harus baik dan bebas dari infeksi. Level bakteri yang lebih dari $10_{\mathrm{s}} / \mathrm{cm}_{2}$ memilki makna klinis yang signifikan. Jumlah bakteri dapat berkurang dengan pemberian antibiotik tpikal dan sistemik. Keberadaan Streptococcus pyogenes pada wound bed merupakan kontraindikasi absolut pada skin grafting. Mekanisme pasti tidak diketahui, namun disebutkan bahwa jenis Streptococcus menghasilkan 
fibrinolisin yang dapat mengganggu pores perlekatan fibrin terhadap graft. $^{15,16}$

Gaya geser atau pergerakan dapat memisahkan graft yang baru terhadap jaringan dibawahnya dan mencegah kontak yang diperlukan untuk hubungan antar kapiler dan kelangsungan hidup selanjutnya. Pergeseran harus diminimalkan sebaik mungkin, dengan memberikan penekanan yang tetap dan mantap, dapat menggunakan busa atau kapas proflavine untuk memastikan kontak yang baik antara graft dan jaringan dibawah. Hal ini harus dapat dipertahankan sampai proses adhesi fibrin awal telah berubah menjadi perlekatan jaringan fibrosa yang kuat.

Tindakan hemostasis yang teliti sangat penting selama operasi untuk mencegah pembentukan hematoma. Langkah-langkah operasi harus direncanakan sebaik mungkin untuk memberikan waktu terlama agar proses hemostatik normal dapat terjadi antara graft dengan resipien. ${ }^{15,16}$

\section{SIMPULAN}

Penggunaan skin flap dan skin graft (flap dan graft) pada rekontruksi kelopak mata dapat menjadi solusi bila defek terlalu besar untuk dilakukan penutupan atau tidak dapat dilakukan penutupan secara primer untuk mengembalikan anatomi dan fungsi kelopak mata. Teknik Rotation flap (flap semisirkular) dengan graft mukosa mulut pada pasien ini terdapat komplikasi yang ditemukan yaitu lagoftalmus sebesar $3 \mathrm{~mm}$ setelah satu bulan post operasi namun dengan teknik ini telah dapat merekonstruksi kelopak mata inferior baik secara fungsi dan anatomi.

\section{SARAN}

Pada rekonstruksi kelopak mata dengan defek terlalu besar untuk dilakukan penutupan atau tidak dapat dilakukan penutupan secara primer, disarankan penggunaan skin flap dan skin graft (flap dan graft) pada rekontruksi kelopak mata sebagai solusi untuk mengembalikan anatomi dan fungsi kelopak mata. Flap dan graft merupakan suatu teknik pada bedah plastik dan rekonstruksi dengan tujuan untuk mengisi dan memperbaiki defek pada suatu luka tertentu.

\section{UCAPAN TERIMA KASIH}

Terimakasih saya ucapkan kepada Ketua Program Studi IImu Kesehatan Mata Program Pendidikan Dokter Spesialis Fakultas Kedokteran Universitas Andalas dan Ketua Bagian IImu Kesehatan Mata RS Dr.M.Djamil Padang yang telah membantu dalam penulisan laporan kasus ini.

\section{DAFTAR PUSTAKA}

1. Andon VR, Knight LV, Seglen PO. Basic principles of lid repair and reconstruction. Clinical AECS Illumination. 2012;12(3):1-11.

2. Cantor LB, Rapuano CJ, Cioffi GA. Orbit, eyelid, and lacrimal system. Singapore: American Academy of Ophthalomology; 2015.

3. Padmini HR, Noronha VJ. Post traumatic lower lid reconstruction by Wolfe Graft: a case report. International Journal of Scientific Study. 2014;2(9):97-9.

4. Morales M, Ghaiy R, Itani K. Eyelid reconstruction. Selected Reading in Plastic Surgery. 2010;11(2): 1-49.

5. Iliff WJ, Pacheco EM. Flaps, graft, and alloplastic materials in lid reconstruction and repair. Duane Foundation Ophthalmology. Edisi ke-6. Lippincott William \& Wilkins; 2007.

6. Chen CM, Mehrara BJ. Principle of surgical flaps. Dalam: Kryger ZB, Sisco M, editor (penyunting). Practical Plastic Surgery. Landes Bioscience; 2007. hlm.49-55.

7. Dolan RW, Tucker SM. Specialized local facial flaps for the eyelid and lips. Dalam: Dolan RW, editor (penyunting). Facial plastic reconstructive, and trauma surgery. Marcel Dekker; 2008.hlm. 201-31.

8. Abdallah AM. Reconstruction of eyelid defects after excision of eyelid tumors. Saudi Journal of Ophthalmology. 2006;20(3):196-204.

9. Korn BS, Kikkawa DO, Cohen SR, Hartstein M. Treatment of lower eyelid malposition with dermis fat grafting. American Academy of Ophthalmology Journal. 2008;115(4):744-51.

10. Thorne $\mathrm{CH}$. Techniques and principles in plastic surgery. Dalam: Beasley. RW, Aston, SJ, editor (penyunting). Grabb\&Smith's Plastic Surgery. Edisi ke-6. Lippincott William\&Wilkins.2007.hlm.3-14 
11. Nesbit RD, Laub DR. Random skin flaps. Medscape 2017 (diakses 8 November 2018). Tersedia dari: http://emedicine.medscape.com/ article/1284569-overview\#showall

12. Clark JM, Wang TD. Skin flap design. Medscape. 2017 (diakses 9 November 2018). Tersedia dari: http://emedicine.medscape.com/article/875968overview\#showall

13. Ray S, Rao K. Full thickness skin grafts. Dalam: Spear M, editor (penyunting). Skin graftsindication, applications and current research. IntechOpen; 2011.hIm.43-54.
14. Venter T, Nthumba P. Skin Grafts (diakses 9 November 2018). Tersedia dari: http://paacs.net/ wp-content/uploads/downloads/2013/03/Chapter-3Skin-Grafts.pdf

15. Khosh MM, Shohet MR. Full-thickness skin grafts. Medscape. 2017 (diakses 9 November 2018). Tersedia dari: http://emedicine.medscape.com/ article/876379-overview

16. Wax MK, Pittman AL. Split-thickness skin grafts. Medscape 2017 (diakses 8 November 2018). Tersedia dari: http://emedicine.medscape.com/ article/876290-overview 